doi: 10.32620/oikit.2021.92.10

УДК 621.923

\title{
Математичне моделювання стану інструменту при електроерозійному алмазному шліфуванні
}

\author{
Національний технічний університет \\ «Харківський політехнічний інститут»
}

\begin{abstract}
У роботі приведена методологія прогнозування показників стану інструменту на основі математичного моделювання характеру взаємодії ріжучого рельєфу круга 3 оброблюваним матеріалом. Це дозволило розкрити закономірності зміни фізичних і технологічних параметрів процесу і їх взаємозв'язок з продуктивністю і зносом кругів в різних умовах електроерозійного алмазного шліфування. Показано, що процес електроерозійного алмазного шліфування, забезпечує стійкий стан рельєфу алмазного круга, стабільні умови взаємодії його робочої поверхні з оброблюваним матеріалом. Це дозволило за допомогою математичної моделі встановити взаємозв'язок факторів та оптимізувати параметри, гарантувати достовірність і відтворюваність результатів. Для створення адекватної моделі розглянута схема процесу шліфування, в якій враховано, що алмазні зерна не мають регулярної геометрії, розташовані на робочій поверхні інструменту на різних рівнях, при роботі зношуються і руйнуються. При аналізі процесу шліфування враховано, що радіус-вектори інструменту і заготовки випадкові, а їх центри обертання зміщуються відносно один одного не тільки внаслідок наявності подач, але і температурних, пружних деформацій. На основі розглянутої схеми процесу шліфування розроблені залежності для обчислення ймовірності видалення матеріалу в будь-якій точці зони контакту 3 урахуванням декількох одночасно протікають процесів формоутворення. Вони дозволяють прогнозувати знімання матеріалу, диференційовано оцінювати вплив окремих фракторів на параметри якості деталі і швидкість протікання процесу. Відкрита структура моделі дає можливість удосконалювати її в міру уточнення входять залежностей, котрі входять до неї. Розроблено динамічну теоретико-імовірнісна модель зносу абразивно-алмазного інструменту з урахуванням ерозійних процесів, що впливають на зв'язку круга. При побудові враховані розмірний знос круга, процеси сколювання і виривання поодиноких алмазних зерен з зв'язки, величини майданчиків зносу і дійсної глибини мікрорізання. Для безпосереднього використання отриманих теоретичних результатів необхідні експериментальні дослідження по визначенню параметрів, що входять до складу моделі.
\end{abstract}

Ключові слова: форма алмазних крайок; глибина мікрорізання; сили різання.

\section{Вступ}

Продуктивність електроерозійного алмазного шліфування визначається умовами взаємодії оброблюваного матеріалу деталі з робочою поверхнею алмазного круга і її станом. Цей стан залежить від властивостей різальних елементів і їх розподілу по висоті, здатності зберігати розвинений ріжучий рельєф. Знаючи розподіл зерен, можна для будь-якої глибини врізання профілю інструмента встановити кількість активних робочих зерен, які здійснюють знімання матеріалу.

Таким чином, розрахунок кількості зерен на поверхні круга, встановлення їх розподілу, аналіз деформації цього розподілу при взаємодії зерен 3 матеріалом, щільності ймовірності товщини зрізу $є$ необхідними передумовами для визначення продуктивності шліфування і зносу алмазного круга.

Зона контакту являє собою область взаємного проникнення різальних крайок в оброблюваний матеріал і виступів матеріалів в проміжки між зернами. До параметрів стану зони відносяться її розміри і форма, співвідношення 
зрізаної і не зрізаної частин металу в кожній області зони, фрізичні процеси фрормоутворення в тому числі: процеси стружкоутворення, тепловиділення, пластичні деформації оброблюваного матеріалу, знос і руйнування інструментального матеріалу, фрізичний і хімічний вплив на матеріали мастильно-охолоджувальної рідини.

\section{Основний матеріал}

Поточний стан робочої поверхні алмазного інструменту може бути охарактеризован відповідними статистичними характеристиками його форми, яка визначає вторинні статистичні характеристики форми оброблюваної деталі. У свою чергу статистичні характеристики фрорми абразивного інструменту визначаються формою різальних крайок, їх числом, розподілом, вихідною фрормою інструменту, матеріалом деталі наявністю на різальних крайках і в порах круга часток оброблюваного матеріалу і т.д.

Одним з найбільш істотних фракторів, що впливають на процес шліфування, $є$ фрорма різальних крайок та їх орієнтація. Вихідна форма вершини зерна може бути представлена параболоїдом обертання (рис.1) [1].

В процесі обробки різальні кромки притупляються, і на вершинах зерен з'являються майданчики зносу, що утворюють усічену вершину. При цьому фрорма майданчиків зносу визначається як вихідної формою кожного з зерен, так і загальними характеристиками фрорми алмазного круга. При цьому в площині вектора швидкості різання вершина зерна має площадку з радіусом округлення, рівним радіусу круга.

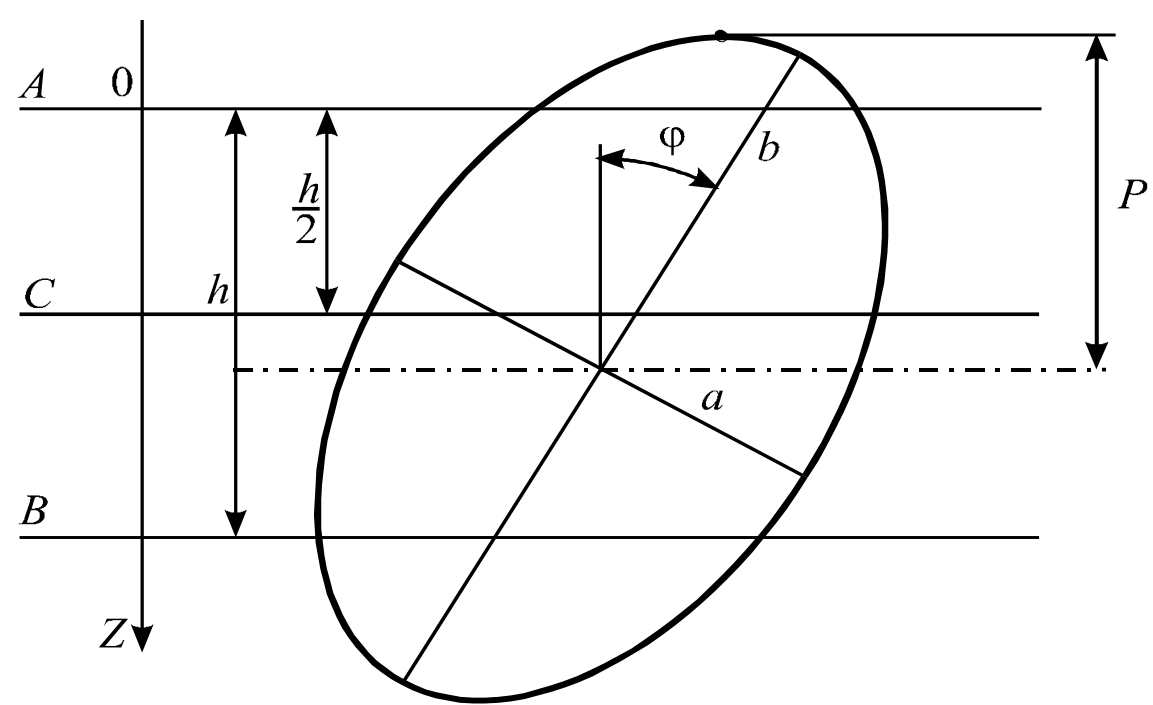

Рис.1 Вихідна форма вершини зерна алмазного круга

Число різальних крайок після дії електричних розрядів визначається по залежностям, наведених в роботі [2]. Число різальних крайок на робочій поверхні інструменту за період його стійкості може змінюватися - збільшуватися безпосередньо після дії електричних розрядів і зменшуватися в процесі шліфрування внаслідок того, що частина зерен 3 різальними крайками руйнується і виривається з зв'язки круга. Руйнування різальної крайки відбувається або в разі перевищення сили різання цієї кромкою межі міцності матеріалу зерна, або у разі перевищення межі міцності зв'язки утримує зерно з 
працюючою кромкою.

Таким чином, для характеристики випадання зерен можна використовувати сили різання, які для умов абразивного шліфування можуть бути розраховані по залежності, отриманої в роботі [3], при електроерозійному алмазному шліфуванні розрахункові залежності необхідно привести до виду:

$$
\left.\begin{array}{cc}
P_{T}=\tau_{C д в} F_{C P} k_{T}\left(1+\mu \frac{k_{H}}{k_{T}}\right), & P_{H}=\tau_{C д В} F_{C P} k_{H}, \\
k_{T}=-\operatorname{tg} \gamma \frac{1+\xi^{2}}{2}+1, & k_{H}=-k_{T} \frac{\operatorname{tg} \gamma}{2}(\xi+1), \\
\operatorname{tg} \gamma=-\frac{\pi}{4} \frac{b}{a}, & F_{C P}=\frac{a b}{m+1} .
\end{array}\right\}
$$

де $\tau_{C Д в}$ - максимальне напруження зсуву матеріалу заготовки; $F_{C P}-$ площа в точці зрізу матеріалу; $\mu$ - коефіцієнт тертя-ковзання зерна по металу; $\gamma-$ передній кут різальної кромки зерна; - величина відносного зсуву матеріалу; $m$ - параметр, що визначає пропорційність еліпса; $a$ - глибина мікрорізання зерном; $b$ - ширина зерна на рівні зрізу матеріалу.

Глибину мікрорізання зерном визначимо із залежності (1), як фактичну глибину різання $t_{f i}$ на і - ом обороті:

$$
a_{i}=t_{f i}=R_{i}+r_{i}-A_{i}
$$

Для розрахунку параметрів сил різання і шорсткості поверхні модель ширини зерна $b$ на рівні $t_{f i}$ може бути використана спрощена залежність:

$$
b_{3}=C_{b} t_{f}^{0.5}
$$

Розглянемо силу закріплення зерна в зв'язці, тому що вона поряд 3 силами різання характеризує викришування і випадання зерен. Для стану круга після дії електричних розрядів подібна залежність приведена в роботі [1]:

$$
\mathrm{P}_{\mathrm{T} . \mathrm{KP}}=\sqrt[3]{\frac{\mathrm{V}_{\mathrm{C}}^{2}}{\left(\mathrm{~V}_{\mathrm{C}}+\mathrm{V}_{\Pi}\right)^{2}}} \times \frac{\mathrm{d}_{0}^{2}\left[\tau_{\mathrm{CB} . \mathrm{P}}\right]}{\mathrm{N}_{2}+\mathrm{N}_{3} \frac{\mathrm{P}_{\mathrm{H}}}{\mathrm{P}_{\mathrm{T}}}},
$$

де $\mathrm{N}_{2}=\frac{8 \mathrm{l}_{01} \mathrm{~d}_{0}^{2} \mathrm{~b}_{\mathrm{c}}}{\pi \mathrm{d}_{0}^{4} \mathrm{~N}_{1}} \times\left(1-\frac{2 \mathrm{x}_{01}}{\mathrm{~d}}\right), \mathrm{N}_{3}=\frac{6 \mathrm{~d}_{0}^{2}}{\pi \mathrm{d}^{2}} \frac{\left(1-\frac{2 \mathrm{a}_{\mathrm{C}}}{\mathrm{d}}\right)}{\left(1-\left(1-\frac{2 \mathrm{~b}_{\mathrm{c}}}{\mathrm{d}}\right)^{3}\right)}$,

$l_{01}=\delta_{c в}+\mathrm{a}_{\mathrm{c}}\left(1-\frac{\mathrm{x}_{01}}{\mathrm{a}_{\mathrm{C}}}\right), b_{c}-$ діаметр майданчика зерна зі зв'язкою; $d_{o}-$ діаметр сфрери, яку можна описати навколо зерна на рівні зв'язки; $d$ - зернистість круга; $x_{01}$ - відстань від осі повороту зерна до центру зерна; $x_{c \kappa}-$ величина вильоту 
зерна з зв'язки після дії електричних розрядів; $a_{c}$ - глибина закладення зерна в зв'язку; $l_{1}$ - відстань від осі повороту зерна під дією тангенціальної сили до рівня зв'язки; $\mathrm{N}_{1}$ - коефріцієнт, що визначає передній кут різання зерна, визначається таблично з роботи [4]; $P_{\mathrm{H}}, \mathrm{P}_{\mathrm{T}}-$ нормальна і тангенціальна складові сили різання відповідно; $V_{c}, V_{n}$ - частина обсягу інструменту, зайнята відповідно зв'язкою і порами; $\left[\tau_{c в . p}\right]$ - гранично допустима напруга зв'язки на розтягнення; $\left[\tau_{c в . с ж}\right]$ - гранично допустима напруга зв'язки на стиск.

3 розглянутих вище формул випливає, що одними з основних параметрів, що визначають утримання зерна на поверхні інструменту і їх випадання 3 зв'язки, $€: a_{c}$ - глибина закладення зерна в зв'язку; $\delta_{c b}-$ величина вильоту зерна з зв'язки. У роботі [5] $\delta_{c в}$ та $a_{c}-$ визначені на інструменті в момент після правки в залежності від ії режимів і характеризують початковий стан круга. Стосовно до умов шліфування 3 введенням в зону обробки додаткової електричної енергії виникає питання моделювання цих параметрів в будь-який момент часу для першого шару зерен, як основних показників стану інструменту. В процесі роботи круга зерно зношується $\delta_{c b}$, і величина його вильоту з зв'язки змінюється:

$$
\delta_{c b i}=\delta_{c B i-1}-h_{3 i-1}+\Delta a_{c i-1},
$$

де $h_{3 i-1}$ - знос зерна при механічному терті на попередньому обороті круга; $\delta_{c в i-1}$ - величина вильоту зерна на попередньому обороті кола; $\Delta a_{c i-1}$ - зміна глибини закладення зерна в зв'язку за оборот:

$$
\Delta a_{c i-1}=a_{c i-1}-a_{c i}=h_{c в i-1}+\Delta r_{\ni p i-1},
$$

де $h_{c в i-1}$ - лінійний знос зв'язки за рахунок тертя з матеріалом заготовки; $\Delta r_{э р i-1}$ - шар зв'язки віддаленої за рахунок ерозійних розрядів; $a_{c i-1}$ - величина закладення зерна в зв'язку на попередньому обороті.

Вираз для розрахунку $\delta_{c в}$ можна записати в наступному вигляді:

$$
\delta_{c B i}=\delta_{c B i-1}-h_{3 i-1}+h_{c B i-1}+\Delta r_{\ni p i-1}
$$

Зі збільшенням висоти профрілю інструменту і зростанням майданчиків зносу зерен підвищується ймовірність випадання найбільш виступаючих елементів з зв'язки. Різальні елементи будуть випадати, коли висота їх закладення в зв'язку буде зменшуватися до критичної позначки $a_{c . к p .}$

При подальшій роботі круга в режимі самозаточування (випадання зерен) верхній шар зерен матиме постійно значення $a_{c}=a_{c . к p . ~}$ Тому для опису роботи круга в усіх режимах запишемо систему:

$$
\begin{array}{ccc}
a_{c i}=a_{c . k p} & n p u & a_{c i}<a_{c . k p} \\
a_{c i}=a_{c i-1}-h_{c в i-1}-\Delta r_{\ni p i-1} & n p u & a_{c i}>a_{c . k p}
\end{array}
$$

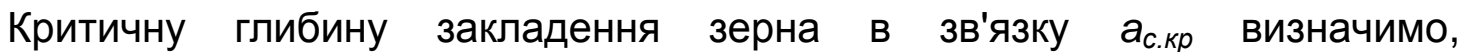
прирівнюючи силу різання одиничним зерном і силу закріплення. Виражаючи 3 отриманого рівняння $a_{c}$, запишемо: 


$$
a_{C . K P}=\frac{1}{N_{4}-\frac{2 P_{T} P_{5}}{P_{T} d}}\left(\begin{array}{l}
\left(\sqrt[3]{\frac{V_{C}^{2}}{\left(V_{C}+V_{\Pi}\right)^{2}}} \times \frac{d_{0}^{2}\left[\tau_{C B}\right]}{\tau_{C Д B} F_{C P} k_{H}}\right)- \\
-N_{4}\left(\delta_{c B}-x_{c B}\right)-N_{5} \frac{P_{H}}{P_{T}}
\end{array}\right),
$$

де $\mathrm{N}_{4}=\frac{8 \mathrm{~d}_{0}^{2} \mathrm{~b}_{\mathrm{C}}}{\pi \mathrm{d}_{0}^{4} \mathrm{~N}_{1}}\left(1-\frac{2 \mathrm{x}_{01}}{\mathrm{~d}}\right), \mathrm{N}_{5}=\frac{6 \mathrm{~d}_{0}^{2}}{\pi \mathrm{d}^{2}\left(1-\left(1-\frac{2 \mathrm{~b}_{\mathrm{C}}}{\mathrm{d}}\right)^{3}\right)}$.

Швидкість зносу вершини виступаючого зерна $\frac{d h_{3 и}}{d \tau}$ характеризується залежністю:

$$
\frac{d h_{3 и}}{d \tau}=R v_{k} h_{\text {отн }} \cdot \int_{0}^{2 \pi} P(\bar{M}) d \phi,
$$

де $h_{\text {отн }}$ - величина відносного зносу зерна, $P(\bar{M})$ - вірогідність не видалення матеріалу, $R$ - радіус круга, $v_{k}$ - частота обертання круга.

У свою чергу швидкість зменшення $S_{n}$ загального числа різальних крайок $n_{3 t}$ пропорційна ймовірності руйнування кожної з крайок $P_{p}$ при одиничному контакті оброблюваної поверхні з абразивним кругом і числу таких контактів за одиницю часу:

$$
S_{n}=P_{p} \cdot n_{3 t} \cdot v_{k},
$$

У той же час в процесі зносу інструменту в роботу з певною ймовірністю можуть вступати нові різальні кромки. Ця ймовірність $P(\xi \leq u)$ визначається межею відносини числа різальних крайок $n_{3}(u)$, що знаходяться в шарі між рівнем $и$ і зовнішньою поверхнею інструменту, до загальної кількості зерен $n_{3}(H)$ ділянки поверхні $S$ :

$$
P(\xi \leq u)=\lim _{s \rightarrow \infty} \frac{n_{3}(u)}{n_{3}(H)},
$$

де $H$ - робочий шар інструменту, в межах якого проводиться підрахунок числа зерен; $\xi$ - відстань зовнішньої поверхні інструменту до рівня $u$.

У припущенні, що в роботу вступають всі абразивні зерна, що лежать в шарі товщиною $\Delta R$, рівному зносу інструменту, число різальних крайок на одиниці його поверхні в момент часу $t$ з урахуванням (10) може бути визначено як:

$$
n_{3 \tau}=n_{30}-\int_{0}^{t} S_{n} d \tau+n_{30} \int_{t_{f}}^{t_{f}+\Delta R(t)} f(u) d u .
$$

В процесі роботи круга внаслідок зносу зерен відбувається зміна рівня и 
як внаслідок зносу найбільш виступаючих $h_{3}(0)$, так і внаслідок зносу інших зерен розглянутого шару з робочими крайками $h_{3}\left(u^{\prime}\right)$.

Для аналізу впливу зносу, на функцію розподілу різальних крайок використовуючи методику, запропоновану в роботі [6] виділимо на поверхні круга після дії електричних розрядів за час шари з однаковим числом вершин ріжучих крайок. Для цього достатньо перемістити умовну зовнішню поверхню на величину зносу найбільш виступаючих зерен $h_{3}(0)$, а рівень $и$ на величину зносу кромок цього рівня $h_{3}\left(u^{\prime}\right)$ (рис. 2).

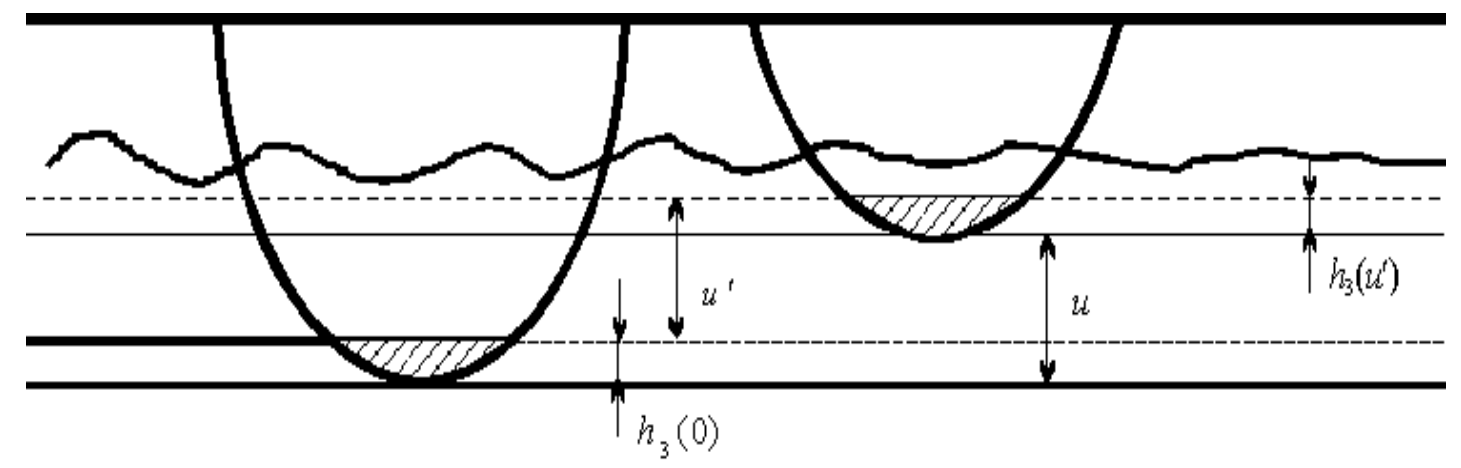

Рис. 2 Схема зміни стану зерен круга

в результаті зносу різальних крайок

Координату рівня від нової умовної поверхні інструменту при цьому позначимо $u^{\prime}$, за схемою з рис. 2 вона визначена як:

$$
u^{\prime}=u+h_{3}\left(u^{\prime}\right)-h_{3}(0) .
$$

Якщо руйнування зерен відсутня, то функція щільності розподілу не змінювалася, тобто

$$
F_{\xi^{\prime}}\left(u^{\prime}\right)=F_{\xi}(u) .
$$

Спільне використання залежностей (13) і (14) дозволяє записати інтегральну функцію щільності ймовірності розподілу різальних крайок у вигляді:

$$
F_{\xi^{\prime}}\left(u^{\prime}\right)=F_{\xi}\left(u^{\prime}+h_{3}(0)-h_{3}\left(u^{\prime}\right)\right) .
$$

Дифреренціальну фрункцію щільності ймовірності розподілу зерен за глибиною алмазного круга можна отримати безпосереднім диференціюванням залежності (15) і після застосування фрормули (14) до правої частини отриманого співвідношення отримати вираз:

$$
f_{\xi^{\prime}}\left(u^{\prime}\right)=f_{\xi}(u)\left[1-\frac{d\left(h_{3}\left(u^{\prime}\right)\right)}{d\left(u^{\prime}\right)}\right] .
$$

Якщо величина зносу різальних крайок пропорційна відстані $H-u^{\prime}$, тобто $h_{3}\left(u^{\prime}\right)=C_{h}\left(H-u^{\prime}\right) \tau$, а щільність розподілу після дії електричних розрядів моделюється ступіневою залежністю виду:

$$
f_{\xi}(u)=C_{f}\left[u^{\prime}+C_{h}\left(H-u^{\prime}\right) \tau-h_{3}(0)\right]^{\chi-1}\left(1+C_{h} \tau\right),
$$

де $C_{h}$ - коефріцієнт форми при апроксимації ширини профрілю зношеного зерна.

В відповідність (12) ймовірність збільшення числа зерен в робочому шарі 
інструменту визначиться інтегруванням по $u^{\prime}(17)$ в межах від $t_{f}$ до $t_{f}+\Delta R(\tau):$

$$
\begin{gathered}
P\left(t_{f}\right)=\frac{C_{f}\left(1+C_{h} \tau\right)\left(\left(t_{f}-C_{h} \tau\left(t_{f}-h_{3}(0)+H\right)\right)^{\chi}-\left(t_{f}-C_{h} \tau\left(t_{f}+H\right)-h_{3}(0)\right)^{\chi}\right.}{\left(1-C_{h} \tau\right) \chi}= \\
=\frac{C_{f}\left(1+C_{h} \tau\right)\left(\left(t_{f}+C_{h} \tau\left(\Delta r+h_{3}(0)\right)\right)^{\chi}-\left(t_{f}-\Delta r C_{h} \tau-h_{3}(0)\right)^{\chi}\right.}{\left(1-C_{h} \tau\right) \chi}
\end{gathered}
$$

Помноживши $P\left(t_{f}\right)$ на $n_{30}$, отримаємо вираз для розрахунку кількості різальних крайок в робочому шарі інструменту:

$$
\begin{gathered}
n_{S_{p}}=\frac{n_{30} C_{f}\left(1+C_{h} \tau\right)\left(\left(t_{f}-C_{h} \tau\left(t_{f}-h_{3}(0)+H\right)\right)^{\chi}-\left(t_{f}-C_{h} \tau\left(t_{f}+H\right)-h_{3}(0)\right)^{\chi}\right.}{\left(1-C_{h} \tau\right) \chi}= \\
=\frac{n_{30} C_{f}\left(1+C_{h} \tau\right)\left(\left(t_{f}+C_{h} \tau\left(\Delta r+h_{3}(0)\right)\right)^{\chi}-\left(t_{f}-\Delta r C_{h} \tau-h_{3}(0)\right)^{\chi}\right.}{\left(1-C_{h} \tau\right) \chi}
\end{gathered}
$$

Швидкість приросту числа зерен може бути визначена безпосереднім диференціюванням за часом співвідношення (19):

$$
\begin{aligned}
& S_{P}=\left(A_{1}^{\chi}-A_{2}^{\chi}\right)\left(A_{3}\left(1+\frac{\left(1+C_{h} \tau\right)}{\left(1-C_{h} \tau\right)}\right)+A_{3}\left(1+C_{h} \tau\right) \times,\right. \\
& \times\left(\chi A_{1}^{\chi-1}\left(\left(A_{2}^{\chi-1}-1\right) \Delta r-h_{3}(0)\right)\right)
\end{aligned}
$$

де $A_{1}=t_{f}+C_{h} \tau\left(h_{3}(0)-\Delta r\right) ; A_{2}=t_{f}-h_{3}(0)-\Delta r C_{h} \tau ; A_{3}=\frac{n_{3}(0) C_{f} C_{h}}{\chi\left(1-C_{h} \tau\right)}$; $\Delta r=t_{f}-H$.

Загальна швидкість зміни числа зерен відповідно (9), (10), (13), (20), що характеризується системою диференціальних рівнянь виду:

$$
\left.\begin{array}{l}
\frac{d n_{3}(\tau)}{d \tau}=S_{p}-S_{n} \\
\frac{d h_{3 u}}{d \tau}=R v_{k} h_{\text {omн }} \cdot \int_{0}^{2 \pi} P(\bar{M}) d \phi
\end{array}\right\},
$$

з початковими умовами $n_{3}(0)=n_{30}, h_{3 и}=0$ при $t=0$.

Вищенаведені співвідношення повинні враховуватися при побудові циклів управління операціями відповідно до методики оцінки динамічних параметрів технологічних систем при обробці деталей в умовах електроерозійного алмазного шліфування.

\section{Висновки}

Створена адекватна модель та розглянута схема процесу шліфування, в якій враховано, що абразивні зерна не мають регулярні геометрії, розташовані 
на робочій поверхні інструменту на різних рівнях, при роботі зношуються і руйнуються. При аналізі процесу шліфрування враховано, що радіус-вектори інструменту і заготовки випадкові, а їх центри обертання зміщуються відносно один одного не тільки внаслідок наявності подач, але і температурних, пружних деформацій.

На основі розглянутої схеми процесу шліфування і основних положень теорії абразивної обробки розроблені залежності для обчислення ймовірності видалення матеріалу в будь-якій точці зони контакту з урахуванням декількох одночасно протікають процесів формоутворення. Вони дозволяють прогнозувати знімання матеріалу, диференційовано оцінювати вплив окремих фракторів на параметри якості деталі і швидкість протікання процесу.

Відкрита структура моделі дає можливість удосконалювати її в міру уточнення залежностей, що входять до неї.

\section{Список літератури}

1. Новоселов Ю. К. Динамика формообразования поверхностей при абразивной обработке / Ю. К. Новоселов. - Саратов: Изд-во Саратов, ун-та, 1979. - 232 c.

2. Теоретические основы резания и шлифования материалов: учеб. пособие / А. В. Якимов, Ф. В. Новиков, Г. В. Новиков, Б. С. Серов, А. А. Якимов. - Одесса : ОГПУ, 1999.-450 с.

3. Aurich J. C., Sudermann H., Braun O. Experimental investigation of burr formation in the surface grinding of tool steel // Proceedings of the Institution of Mechanical Engineers, Part B: Journal of Engineering Manufacture. 2006. № 4 (220). C. 489-497.

4. Grabchenko A. I., Pyzhov I. N., Kultyshev S. A. Grinding plane faces with metallic-bond diamond wheels // Soviet engineering research. 1990. № 7 (10). C. 117-119.

5. Pandit S. M., Sathyanarayanan G. New approach to the analysis of wheelworkpiece interaction in surface grinding. 1981.C. 275-282.

6. Wu, J., Cong, W., Williams, R.E., Pei, Z.J. Stochastic modeling and analysis of rotary ultrasonic machining 2009.C. 283-292.

\section{References}

1. Novoselov, Yu 1979, Dinamika formoobrazovaniya poverkhnostey pri abrazivnoy obrabotke, Izd-vo Saratov, un-ta, Saratov.

2. Yakimov, A, Novikov, F, Novikov, G, Serov, B \& Yakimov, A 1999, Teoreticheskiye osnovy rezaniya i shlifovaniya materialov, OGPU, Odessa.

3. Aurich, J.C., Sudermann, H., Braun, O., 2006. Experimental investigation of burr formation in the surface grinding of tool steel. Proceedings of the Institution of Mechanical Engineers, Part B: Journal of Engineering Manufacture 220, pp. 489497.

4. Grabchenko, A.I., Pyzhov, I.N., Kultyshev, S.A., 1990. Grinding plane faces with metallic-bond diamond wheels. Soviet engineering research 10, pp. 117-119.

5. Pandit, S.M., Sathyanarayanan, G., 1981. New approach to the analysis of wheel-workpiece interaction in surface grinding. Presented at the Manufacturing Engineering Transactions, pp. 275-282.

6. Wu, J., Cong, W., Williams, R.E., Pei, Z.J., 2009. Stochastic modeling and analysis of rotary ultrasonic machining. Presented at the Proceedings of the ASME 
International Manufacturing Science and Engineering Conference 2009, MSEC2009, pp. 283-292.

Надійшла до редакції 21.06.2021, розглянута на редколлегії 22.06.2021.

\section{Mathematical modeling of the tool state at electroerosive diamond grinding}

The methodology of forecasting of indicators of a condition of the tool on the basis of mathematical modeling of character of interaction of a cutting relief of a circle with the processed material is resulted in work. This revealed the patterns of changes in physical and technological parameters of the process and their relationship with the productivity and wear of the wheels in different conditions of EDM diamond grinding. It is shown that the process of EDM diamond grinding provides a stable state of relief of the diamond wheel, stable conditions of interaction of its working surface with the processed material. This allowed using a mathematical model to establish the relationship of factors and optimize the parameters, to ensure the reliability and reproducibility of the results. To create an adequate model, the scheme of the grinding process is considered, which takes into account that diamond grains do not have a regular geometry, are located on the working surface of the tool at different levels, wear and break during operation. When analyzing the grinding process, it is taken into account that the radius vectors of the tool and the workpiece are random, and their centers of rotation are shifted relative to each other not only due to the presence of feeds, but also temperature, elastic deformations. Based on the considered scheme of the grinding process, dependences are developed to calculate the probability of material removal at any point of the contact zone, taking into account several simultaneously occurring molding processes. They allow you to predict the removal of material, differentiated to assess the impact of individual factors on the quality parameters of the part and the speed of the process. The open structure of the model makes it possible to improve it as you refine the incoming dependencies that are part of it. A dynamic theoretical-probabilistic model of wear of an abrasive-diamond tool taking into account the erosion processes affecting the wheel connection has been developed. The construction takes into account the dimensional wear of the circle, the processes of chipping and uprooting of single diamond grains from the bond, the size of the wear areas and the actual depth of microcutting. For direct use of the received theoretical results experimental researches on definition of the parameters which are a part of model are necessary.

Keywords: shape of diamond edges; depth of microcutting; cutting force.

\section{Математическое моделирование состояния інструмента при электроэрозионной алмазном шлифовании}

В работе приведена методология прогнозирования показателей состояния инструмента на основе математического моделирования характера взаимодействия режущего рельефа круга с обрабатываемым материалом. Это позволило раскрыть закономерности изменения фризических и технологических параметров процесса и их взаимосвязь с производительностью и износом кругов в различных условиях электроэрозионного алмазного шлифования. 
Показано, что процесс электроэрозионного алмазного шлифования, обеспечивает устойчивое состояние рельефа алмазного круга, стабильные условия взаимодействия его рабочей поверхности с обрабатываемым материалом. Это позволило с помощью математической модели установить взаимосвязь фракторов и оптимизировать параметры, гарантировать достоверность и воспроизводимость результатов. Для создания адекватной модели рассмотрена схема процесса шлифования, в которой учтено, что алмазные зерна не имеют регулярной геометрии, расположенные на рабочей поверхности инструмента на различных уровнях, при работе изнашиваются и разрушаются. При анализе процесса шлифования учтено, что радиус-вектора инструмента и заготовки случайные, а их центры вращения смещаются относительно друг друга не только вследствие наличия подач, но и температурных, упругих деформаций. На основе рассмотренной схемы процесса шлифования разработаны зависимости для вычисления вероятности удаления материала в любой точке зоны контакта с учетом нескольких одновременно протекающих процессов формообразования. Они позволяют прогнозировать съем материала, диффреренцированно оценивать влияние отдельных фракторов на параметры качества детали и скорость протекания процесса. Открытая структура модели дает возможность совершенствовать ее по мере уточнения, входящих в нее зависимостей. Разработана динамическая теоретико-вероятностная модель износа абразивно-алмазного инструмента с учетом эрозионных процессов, влияющих на связку круга. При построении учтены размерный износ круга, процессы скалывания и вырывания отдельных алмазных зерен из связки, величины площадок износа и действительной глубины микрорезания. Для непосредственного использования полученных теоретических результатов необходимы экспериментальные исследования по определению параметров, входящих в состав модели.

Ключевые слова: фрорма алмазных кромок; глубина микрорезания; силы резания.

\section{Відомості про автора:}

Стрельчук Роман Михайлович - кандидат технічних наук, кафедра інтегрованих технологій машинобудування ім. М. Ф. Семка, Національний технічний університет «Харківський політехнічний інститут», м Харків, Україна; e-mail: r.m.strelchuk@gmail.com; ORCID: 0000-0002-7221-031X.

\section{About the Author:}

Strelchuk Roman, Cand. of Tech. Sc., Department of INTEGRATED Technologies of Mechanical Engineering named after M.F. Semko, National Technical University «Kharkiv Polytechnic Institute», Kharkiv, Ukraine; e-mail: r.m.strelchuk@gmail.com; ORCID: 0000-0002-7221-031X. 